\title{
Vitamin D Update
}

\author{
Mary S. Matsui ${ }^{1}$
}

Accepted: 17 September 2020 / Published online: 14 October 2020

(C) Springer Science+Business Media, LLC, part of Springer Nature 2020

\begin{abstract}
Purpose The goal of this review is to provide an update in the field of vitamin D, in particular, the role of vitamin D in nonskeletal health, the complexity of providing patient guidance regarding obtaining sufficient vitamin $\mathrm{D}$, and the possible involvement of vitamin D in morbidity and mortality due to SARS-CoV-2 (COVID-19).

Recent Findings In addition to bone health, vitamin D may play a role in innate immunity, cardiovascular disease, and asthma. Although rickets is often regarded as an historical disease of the early twentieth century, it appears to be making a comeback worldwide, including "first-world" countries. Broad-spectrum sunscreens (with high UVA filters) that prevent erythema are unlikely to compromise vitamin D status in healthy populations.

Summary New attention is now focused on the role of vitamin D in a variety of diseases, and more individualized patient recommendation schemes are being considered that take into account more realistic and achievable goals for achieving sufficient vitamin D through diet, supplements, and sun behavior.
\end{abstract}

Keywords Vitamin D $\cdot$ Pigmentation $\cdot$ Ultraviolet light $\cdot$ Rickets $\cdot$ Osteomalacia $\cdot$ Sunscreen

\section{Introduction}

In the last 10 years, over 41,000 peer-reviewed research studies have been published on vitamin $\mathrm{D}$, and since its original discovery as a sunlight-generated factor important to bone health, a more complex story of vitamin D has continued to evolve. Vitamin D, technically not a vitamin, has been linked not just to rickets in children and osteomalacia in adults, but also has been suggested to play a role in diabetes, celiac disease, asthma, atopic dermatitis, tuberculosis, and, most recently, COVID-19. This review will briefly summarize fundamental, well-established aspects of vitamin D and human health and then will also discuss (a) some of the most recent work related to vitamin D and non-skeletal-associated health issues; (b) the complexity of establishing meaningful vitamin D measurement metrics and assessing vitamin D status; c)decisionmaking for obtaining vitamin $\mathrm{D}$ through diet, supplements, or sun exposure; (d) the impact of skin type, pigmentation, and sunscreen on vitamin D levels; and (e) evidence for a potential

This article is part of the Topical Collection on Photodermatology

Mary S. Matsui

Teaneck, NJ, USA influence of vitamin D on the mortality and morbidity of COVID-19 through modulation of the pro-inflammatory cytokine response and respiratory response to the virus.

\section{Vitamin D Basics}

Some would urge us to move away from the nomenclature of vitamin $\mathrm{D}$ as a vitamin and, instead, acknowledge that vitamin D3 is a prohormone produced in skin through ultraviolet irradiation of 7-dehydrocholesterol (7DHC or provitamin D3) [1•]. This previtamin D3 is biologically inert and must undergo thermal isomerization and two hydroxylations. The first hydroxylation occurs in the liver and converts vitamin $\mathrm{D}$ to 25-hydroxyvitamin D [25(OH)D], also known as calcidiol. Physiologically active 1,25-dihydroxyvitamin D $[1,25(\mathrm{OH}) 2 \mathrm{D}]$, or calcitriol, is then synthesized primarily in the kidney.

The importance of vitamin D for calcium absorption and bone health is undisputed $[2,3]$. The classic function of vitamin D is to promote calcium absorption in the gut and maintain adequate serum calcium and phosphate concentrations necessary for normal mineralization of bone. Rickets in children and osteomalacia in adults results from insufficient vitamin D [1•]. Together with calcium, vitamin D helps protect 
older adults from osteoporosis. There is strong, consistent evidence supporting the role of vitamin D in childhood bone health, although most studies have been done in a limited range of skin types, as exemplified in a very recent report showing that high-dose vitamin $\mathrm{D}$ supplementation during pregnancy improved bone health in children [4]. In this case, all participants were white and Danish.

Globally, rickets and vitamin D deficiency remain a significant public health problem even in highly developed countries [5••], despite much research and many government and nongovernmentally funded programs. In Europe, little vitamin $\mathrm{D}$ is made endogenously in the skin of individuals during the winter months [ $\left.1^{\bullet}\right]$, and yet vitamin D fortification of foods is largely absent. In the view of many scientists in the vitamin D field, the recommended dietary allowance is too low. Recommendations for vitamin D3 at 2000 IU/day are being considered, an intake which should be safe and remain below toxic levels [1•]. Factors contributing to a modern "third wave" of rickets have been reviewed recently [5••] from prospective surveillance studies of vitamin D deficiency rickets in Australia, Canada, and New Zealand, as well as multiple retrospective studies from across the globe. In part, this third wave is believed to be caused by reduced UVB exposure due to sun avoidance (sunscreen, clothing, cultural behavior) and a shift toward indoor work.

Malabsorption syndromes such as celiac disease, short bowel syndrome, gastric bypass, and cystic fibrosis can trigger vitamin D deficiency [6]. Medications such as phenobarbital, carbamazepine, dexamethasone, nifedipine, spironolactone, clotrimazole, and rifampin induce hepatic p450 enzymes which can accelerate the degradation of vitamin $D$ and thereby lead to vitamin D deficiency. Chronic liver disease and chronic kidney disease increase the risk for vitamin D deficiency due to the dependence on these organs for vitamin D activation. The prevalence of patients with vitamin D deficiency is highest in the elderly, obese, nursing home residents, and hospitalized patients [6]. The issue of vitamin D deficiency in populations who have higher melanin content and/or use extensive skin coverage will be discussed separately.

According to the NIH, serum concentration of $25(\mathrm{OH}) \mathrm{D}$ is the best indicator of vitamin D status. It reflects total vitamin D produced cutaneously as well as obtained through food and supplements and has a fairly long circulating half-life of 15 days. $25(\mathrm{OH}) \mathrm{D}$ functions as a biomarker of exposure, but it is not clear to what extent $25(\mathrm{OH}) \mathrm{D}$ levels also serve as a biomarker of physiological disease or more subtle conditions or indicate the amount of vitamin D stored in body tissues (primarily adipose tissue). In contrast to $25(\mathrm{OH}) \mathrm{D}$, circulating $1,25(\mathrm{OH}) 2 \mathrm{D}$ is not a good indicator of vitamin D status. Levels of $1,25(\mathrm{OH}) 2 \mathrm{D}$ do not typically decrease until vitamin $\mathrm{D}$ deficiency is severe. Table 1 shows the current serum concentrations and interpretations from the Institute of Medicine [7•]. In addition, because the two test protocols used to measure
25(OH)D show some variability among laboratories that conduct the analyses, a standard reference material for 25(OH)D was developed to improve confidence in the result [8].

Although from Table 1 it would appear that there exists one set of ideal values for serum vitamin $\mathrm{D}$, the situation is somewhat more complex. A slightly alternate rule of thumb is the following [6]: levels of $25(\mathrm{OH}) \mathrm{D}$ less than $20 \mathrm{ng} / \mathrm{mL}$ indicate vitamin $\mathrm{D}$ deficiency, while levels below $30 \mathrm{ng} / \mathrm{mL}$ indicate vitamin D insufficiency. Levels of 25(OH)D between 30 and $50 \mathrm{ng} / \mathrm{mL}$ are generally regarded to be optimal levels; however, a number of variables, including race and age, add complexity [6]. A more thorough discussion of vitamin D assay standardization and recommendation guidelines is provided by Sempos and Binkley [9]. In any case, the categories of vitamin $\mathrm{D}$ sufficiency or deficiency are based on the classic function of vitamin D, bone health. Again, based on bone health parameters, vitamin D levels can also be referred to as deficient, insufficient, sufficient, or optimal vitamin D status. The severity of vitamin D deficiency is divided into mild, moderate, and severe. But what about other conditions for which vitamin D may have some modifying actions? There are numerous and conflicting studies that suggest that there may be an association between vitamin D deficiency and cancer, cardiovascular disease, diabetes, autoimmune diseases, asthma, atopic dermatitis, and depression. If indeed, vitamin $\mathrm{D}$ status is a modifying factor for these health issues, and it cannot be assumed that the ideal $25(\mathrm{OH}) \mathrm{D}$ serum values for prevention of rickets and osteomalacia would prevent or modify these other diseases.

\section{Extra-Skeletal Functions of Vitamin D}

It is now recognized that many cells in the body express vitamin D receptors (VDR) which modulate cell proliferation, differentiation, and apoptosis and also regulate gene expression associated with modulation of cell growth, neuromuscular and immune function, and inflammation and may help regulate antimicrobial peptides $[10 \bullet-14]$. Several cells involved in immune function express VDR and CYP27B1, which suggests that the active form of vitamin $D$, $1,25(\mathrm{OH}) 2 \mathrm{D}$, may control immune function at different levels $[10 \bullet \cdot$. Vitamin D is known to regulate parathyroid growth and parathyroid hormone production; it plays a role in the islet cells of the pancreas and may help in suppression of certain autoimmune diseases and some cancers. There are many suggestions that deficiencies in vitamin D levels are linked to conditions such as rheumatoid arthritis, multiple sclerosis, Alzheimer's disease, and schizophrenia (for reviews, see $[10 \bullet, 13 \bullet \cdot])$. Prospective studies have reported inverse correlations between $25(\mathrm{OH}) \mathrm{D}$ serum levels and cardiovascular disease, serum lipids, inflammation, disorders of glucose metabolism, weight gain, mood disorders, declining cognitive 
Table 1 Serum 25Hydroxyvitamin D [25(OH)D] concentrations and health*. From $[7 \cdot]$

\begin{tabular}{lll}
\hline $\mathrm{nmol} / \mathrm{L}^{* *}$ & $\mathrm{ng} / \mathrm{mL}^{*}$ & Health status \\
\hline$<30$ & $<12$ & $\begin{array}{c}\text { Associated with vitamin D deficiency, leading to rickets in infants and children and } \\
\text { osteomalacia in adults } \\
\text { Generally considered inadequate for bone and overall health in healthy individuals }\end{array}$ \\
30 to 50 & 12 to 20 & $\begin{array}{l}\text { Generally considered adequate for bone and overall health in healthy individuals } \\
>50\end{array}$ \\
$>120$ & $>50$ & $\begin{array}{c}\text { Emerging evidence links potential adverse effects to such high levels, particularly } \\
>150 \mathrm{nmol} / \mathrm{L}(>60 \mathrm{ng} / \mathrm{mL})\end{array}$ \\
\hline
\end{tabular}

*Serum concentrations of $25(\mathrm{OH}) \mathrm{D}$ are reported in both nanomoles per liter $(\mathrm{nmol} / \mathrm{L})$ and nanograms per milliliter $(\mathrm{ng} / \mathrm{mL})$

$* * 1 \mathrm{nmol} / \mathrm{L}=0.4 \mathrm{ng} / \mathrm{mL}$ function, and Alzheimer's disease. However, no effect of vitamin D supplementation has been demonstrated for these outcomes, so the proximal relationship could be genetic, cultural behavior, or other confounding. First suggested over 30 years ago, vitamin D is now often referred to as a "wellknown" regulator of innate immunity [10••]. The apparent mechanism for this is vitamin D enhancement of defensin $\beta 2$ and cathelicidin antimicrobial peptide (CAMP) production, increasing their antimicrobial activity [15]. A thorough review of vitamin D's regulatory function in both innate and acquired immunity can be found in Wei and Christakos [15]. The biologically active form of vitamin $\mathrm{D}, 1,25(\mathrm{OH}) 2 \mathrm{D}$, modulates innate and adaptive immunity via regulation of at least 15 genes by the VDR [16]. $1,25(\mathrm{OH}) 2 \mathrm{D}$ upregulates CAMP not only in monocytes/ macrophages but also in other cells participating in the innate immune system. That said, there are insufficient data at this time to recommend any specific vitamin D dosage or treatment regimen for asthma, autoimmune diseases, multiple sclerosis, or other conditions.

There is confusing and sometimes contradictory evidence for the therapeutic use of vitamin D to treat nonskeletal conditions. For example, although treatment with $1,25(\mathrm{OH}) 2 \mathrm{D}$ was shown to be effective in reducing respiratory infections in asthma patients, and suboptimal serum $25(\mathrm{OH}) \mathrm{D}$ in childhood may have adverse effects on tuberculosis and asthma, vitamin D supplementation in pregnancy does not appear to prevent school-age asthma [17]. In a study on vitamin D levels and susceptibility to asthma and atopic dermatitis, no evidence was found for genetically determined low 25(OH)D levels to be linked to an increased risk of either conditions [18]. Initial reports indicate that vitamin D and omega3 supplements failed to reduce risk of cancer or heart events in a 5-year trial of nearly 26,000 healthy US adults [19]. This is, in part, why there is currently active discussion over both the recommended levels of vitamin $\mathrm{D}$ as well as the testing methods used to assess adequacy for health and prevention of diseases.

\section{Vitamin D Intake Recommendations, Evaluation of Sufficiency, and Sun Exposure}

Recommendations for optimum vitamin D levels, for obtaining a healthy level of vitamin D and even for assessment methods, are currently not uniform across the globe. To some extent, this is because relevant factors vary: vitamin $\mathrm{D}$ food fortification regulations, the strength of ambient ultraviolet radiation (UVR), levels of smog, culture and ethnicity, skin phototype, chronological age, and ease and accuracy of specific clinical laboratory measurements. For example, some geographic regions with strong sun have a very high prevalence of rickets [20]. The American Academy of Dermatology (AAD) is regarded as a primary resource for good practice in the field of skin health and related medical specialties. The AAD position statement on vitamin $\mathrm{D}$ can be accessed online [21] and lists the recommended dietary allowance (RDA) and the upper limit values for both calcium and vitamin D intake that should cover "97.5\% of the normal healthy population." The optimum vitamin D intake varies by age: for children under 1 year, the RDA is $400 \mathrm{IU} /$ day; between 1 year and 70 years, the RDA is $600 \mathrm{IU} /$ day; and for people over 70 , the RDA is $800 \mathrm{IU} /$ day. These RDA guidelines are based on AAD guidelines that promote minimal or no sun exposure primarily due to the risk of skin cancer associated with sun exposure. The American Cancer Society also does not support increasing vitamin D levels through sun exposure. The Cancer Council of Australia has slightly eased its sun protection message concerning sunscreen, outdoor clothing, and hats. Protection from the sun is currently recommended by the World Health Organization when the UVR index is $\geq 3$ [22]. In general, the paradigm accepted is that an initial linear dose-response relationship exists between exposure to UV radiation and change in concentration of $25(\mathrm{OH}) \mathrm{D}$, followed by a plateau with continuing exposures over a longer period of time. 
Because UVR from the sun and tanning beds can lead to the development of skin cancer, sun exposure (natural) or indoor tanning (artificial) is strongly discouraged. Instead, it is recommended that vitamin D be supplied from a "healthy diet," which includes naturally enriched vitamin D foods, fortified foods and beverages, and/or vitamin supplements while practicing sun protection. Unfortunately, it is almost impossible to achieve a satisfactory vitamin $\mathrm{D}$ intake from diet alone, since it is found at significant levels in only a few commonly consumed foods. Fat-soluble molecule is found almost exclusively in oily fish such as salmon, sardines, herring and mackerel, liver, egg yolks, and fortified foods. Since dietary sources are unlikely to be sufficient, especially for vegetarians and vegans, supplements are necessary to obtain the RDA. The US Department of Agriculture's (USDA's) websites (https:// fdc.nal.usda.gov/index.html.) can be searched for recommended healthy eating guidelines, the nutrient content of many foods, and a list of foods containing vitamin D. In contrast, one comprehensive review [6] concluded that $30 \mathrm{~min}$ of sunshine daily with over $40 \%$ of skin surface area is required to prevent vitamin $\mathrm{D}$ deficiency (although surface area numbers seem to vary greatly). The difficulty of promulgating simple blanket recommendations as pathways to optimal vitamin D status is well described by Macdonald et al. [23]. This same reference describes a survey of multiple ethnic groups which demonstrated the difficulty (if not impossibility) of reaching optimal vitamin D levels if no sun exposure is considered safe. Most women would find it almost impossible to achieve satisfactory vitamin D status if they had to rely on their current diets. Other measures including fortification of additional foods may have to be considered. Several different vitamin D fortification programs have been initiated across the globe [24].

In contrast to the $\mathrm{AAD}$ guidelines that advise against any sun exposure, recommendations from the National Health Service of the UK [25] states this: "From about late March/early April to the end of September, most people should be able to get all the vitamin D we need from sunlight." Clearly, one issue that is immediately apparent is the seasonality of vitamin D levels in certain latitudes. This brings up other key questions in the world of vitamin D. Is there such a thing as "sensible" sun exposure? Are vitamin D guidelines a "one size fits all" or should they be more nuanced to respect the range of human pigmentation and culture? For example, the recommendations and sufficiency numbers do not take into account an almost complete lack of data from Africa and South America [13••]. One recent editorial goes so far as to say that "vitamin D guidelines development is in a state of paralysis" due to a lack of agreement on the parameters for the terms insufficiency, sufficiency, and toxicity based on $25(\mathrm{OH}) \mathrm{D}$ concentrations [9]. Further, the commentary urges that a set of recommendations based on work of the Vitamin D Standardization Program (VDSP) paves the way for development of rational universal vitamin $\mathrm{D}$ status guidelines.
Although it is believed that most vitamin D (about 80\%) is acquired from solar exposure, sunscreen use is an important tool in prevention of skin cancer and is strongly recommended by the dermatology community. UVB wavelengths (280 $320 \mathrm{~nm}$ ) are absorbed by DNA and result in direct damage in the form of cyclobutane pyrimidine dimers (CPDs) and other mutagenic events that ultimately lead to nonmelanoma skin cancer and melanoma. UVA wavelengths $(320-400 \mathrm{~nm})$ generate oxidative stress which is associated primarily with photoaging but can also promote skin cancer. Unfortunately, the same UVB wavelengths absorbed by DNA and that cause DNA mutations are also those that induce photoconversion of 7-dehydrocholesterol, to previtamin D3. One of the most important questions to ask then, with regard to the issue of sun avoidance and vitamin $\mathrm{D}$, is directed toward the balance between (a) sunscreen use and UVR generation of vitamin D and (b) the efficacy of sunscreen to prevent UVR-induced DNA damage. A consensus review published in 2019 [26] concluded that broad-spectrum sunscreens (with high UVA filters) that prevent erythema are unlikely to compromise vitamin D status in healthy populations and that daily and recreational photoprotection does not compromise vitamin D synthesis. Vitamin D screening should be used to monitor patients with photosensitivity disorders, who require the most rigorous photoprotection combined with vitamin D supplements [27••]. Improved vitamin D status by UVR is always associated with the possibility of higher DNA damage and skin cancers; however, production of vitamin D may be optimized and skin DNA damage minimized, by increasing the body surface area exposed and decreasing the UVB dose per unit area $[13 \cdot \bullet]$.

One group has examined the relationship between sunscreen use and vitamin D production in some detail [26, $28 \cdot \bullet, 29]$. A study of sunscreen use in Polish volunteers on vacation in Tenerife had both interventional and observational groups and was able to monitor the effect of two SPF 15 sunscreens over 1 week [26, 29]. One sunscreen had a high UVA protection factor (UVA-PF), while the second had low UVA protection. The authors were able to make the important conclusion that sunscreens may be used to prevent sunburn yet allow vitamin D synthesis, although with the caveat that the absence of sunburn does not necessarily mean the absence of DNA mutations [30]. However, concern about unrepaired mutagenic DNA lesions should be tempered by evidence that efficient repair occurs within 12 to $48 \mathrm{~h}$, although there is significant individual variation in this ability [30]. In the Tenerife study, both high UVA and low UVA sunscreens prevented sunburn, but subjects using the high UVA sunscreen had higher levels of serum 25(OH)D at the conclusion of the study. These findings were attributed to the fact that high UVA sunscreen allows transmission of more UVB than low UVA sunscreen. Another very important study on sun exposure and vitamin D levels followed Polish children over 
12 days at a Baltic Sea summer camp [31]. Relatively low daily UV radiation doses resulted in a modest but significant improvement in $25(\mathrm{OH}) \mathrm{D}(24 \%)$ but a very much greater increase in CPD (1162\%). DNA damage was worse in skin types I/II. This conundrum is reflected in a recent global consensus on rickets prevention that was unable to recommend a safe UVR exposure level to enhance vitamin D status [32].

It has been argued, following in vitro assays, that vitamin D itself reduces the risk of skin cancer by several mechanisms [33-35]. Under laboratory conditions, DNA photolesions can be reduced in irradiated skin cells treated with 1,25(OH)2D. One mechanism for this may relate to the increases in p53 and nucleotide excision repair observed within hours after UVR exposure in keratinocytes and melanocytes treated with $1,25(\mathrm{OH}) 2 \mathrm{D}$ (1 or $10 \mathrm{nM}$ ) or vitamin $\mathrm{D}$ analogs. There was a corresponding reduction in CPDs in UV-irradiated skin cells treated with vitamin D compounds. The indirect DNA damage and the reduction in DNA repair that is normally caused by nitric oxide products may also be reduced by vitamin D compounds. A group in Cleveland reported data from an exploratory study in which high oral doses of vitamin D3 resulted in a sustained reduction in skin redness after experimental sunburn, as well as less epidermal structural damage, reduced expression of pro-inflammatory markers in the skin, and a gene expression profile characterized by upregulation of skin barrier repair genes [11].

\section{Vitamin D and Skin of Color}

One barrier to establishing recommendations for sensible sun exposure is the impact of human skin pigmentation and genetic polymorphisms on the response to UVR. These are still largely unknown variables. A careful literature review of vitamin D and the impact of pigmentation was published in 2015 [36 $]$ and noted that a better understanding of how and how much melanin influences vitamin $\mathrm{D}$ photosynthesis is critical to meaningful public health messages. The research is difficult to integrate due to variations in study methodology, including the source, dose and frequency of UV irradiation, phototype classification, measurement methods for vitamin D, and the lack of information on relevant genetic polymorphisms. However, on balance, the review team concluded that more highly pigmented skin has less effective photoproduction of vitamin D and 25-hydroxyvitamin D. The ratio of sun exposure to pigmentation level to achieve vitamin D sufficiency remains uncertain.

A recent 4-week study of 71 school children [37] controlled for time spent outdoors and assessed the contribution of clothing coverage, initial vitamin D levels, skin color, and other variables to the serum vitamin D levels at the conclusion of the study. The subjects were Fitzpatrick skin phototypes IV and $\mathrm{V}$ with a range of melanin levels. For all subjects, there was a significant increase in serum $25(\mathrm{OH}) \mathrm{D}$ at the conclusion of the study compared with baseline, and a greater increase in serum vitamin D was seen in children with the lowest initial values. Melanin levels were inversely correlated with the increase in vitamin D levels. In a study of racially diverse children in Boston, most of the variability in $25(\mathrm{OH}) \mathrm{D}$ was correlated with constitutive skin color [38].

The correlation between skin color and serum levels of $25(\mathrm{OH}) \mathrm{D}$ is usually attributed to the photoprotective properties of melanin. However, there may be additional variables in play which may influence the ultimate health consequences. In a recent study, black Americans $(n=2085)$ had lower concentrations of $25(\mathrm{OH}) \mathrm{D}$, but also lower concentrations of vitamin $\mathrm{D}$ binding protein, than white Americans. The consequence of this was similar (calculated) levels of bioavailable 25(OH)D. This may explain why people of color with low total $25(\mathrm{OH}) \mathrm{D}$ had a higher average bone mineral density than the white group with similar 25(OH)D concentrations. Furthermore, it may imply that bone health is more accurately reflected by the concentration of bioavailable, rather than total, $25(\mathrm{OH}) \mathrm{D}$.

Taken together, the limited data available suggests that there should be some caution about attributing the observed lower levels of vitamin D in skin of color (SOC) simply to a blocking effect of melanin. A very recent rigorously performed and analyzed study was just published that indicates melanin to have less impact on vitamin D levels than previously thought, possibly due to the spatial positions of melanin and 7-dehydrocholesterol in human skin [39••]. A brief review of confounding related to the question of pigment, UVRrelated skin cancers, and serum vitamin D levels can also be found in a 2015 review [13••].

\section{The Role of Vitamin D as a Possible Modulator of Susceptibility, Morbidity, and Mortality in SARS-CoV-2 (COVID-19)}

That vitamin D should play a role in COVID-19 is not unexpected, since there has been believed to be a link between vitamin D deficiency and respiratory disease for over 100 years. Observational studies have reported independent associations between low serum concentration of 25 hydroxyvitamin D and susceptibility to acute respiratory tract infections [40]. Vitamin D deficiency is associated with an increased risk of the acute respiratory distress syndrome (ARDS), intensive care admission, and mortality in patients with pneumonia [41]. In a systematic review and metaanalysis of 25 randomized controlled studies, Martineau et al. found that vitamin D protected against acute respiratory tract infection overall [42]. Patients who were severely vitamin D deficient experienced the most benefit. Subgroup analysis revealed that daily or weekly vitamin D supplementation without additional bolus doses protected against acute 
respiratory tract infection, whereas regimens containing large bolus doses did not. Among those receiving daily or weekly vitamin $\mathrm{D}$, protective effects were strongest in those with profound vitamin $\mathrm{D}$ deficiency at baseline, although those with higher baseline 25-hydroxyvitamin D concentrations also experienced benefit. The interaction of vitamin D status and susceptibility to SARS-CoV-2 is currently being investigated [43-45••].

Most immune cells express the VDR and actively convert $25(\mathrm{OH}) \mathrm{D}$ into $1,25(\mathrm{OH}) 2 \mathrm{D}$, its active form. VDR signaling has a suppressive role on autoimmunity and an antiinflammatory effect, promoting dendritic cell and regulatory $\mathrm{T}$ cell differentiation and reducing Th 17 cell response and inflammatory cytokine secretion (with relevance to the COVID-19 induced cytokine storm). Also mentioned earlier, vitamin $\mathrm{D}$ is thought to have a regulatory effect on innate immunity. There is no general consensus on the desired level of $25(\mathrm{OH}) \mathrm{D}$ to achieve immunomodulatory effects; thus, there is no current indication for vitamin D supplementation in specific infections and/or autoimmune diseases. However, Dr. Anthony Fauci, director of the National Institute of Allergy and Infectious Diseases, in a recent interview by JAMA, agreed that "if you are vitamin D deficient, you might have a poor outcome or a greater chance of getting into trouble with an infection" (JAMA Medical News \& Perspectives, June 8,2020$)$. The most vulnerable group with respect to COVID-19, the aging population, also has a high proportion of individuals with deficient vitamin D levels. Further studies have been both proposed (at least one clinical trial is registered with the NIH) and initiated to clarify the contribution of vitamin D levels to susceptibility and the severity of response to COVID-19 as well as the use of vitamin D supplementation as a possible therapeutic agent $[43 \bullet \bullet-45 \bullet \bullet$.

\section{Conclusions}

Vitamin D deficiency is a major global public health issue with vitamin $\mathrm{D}$ deficiency rickets at significant levels even in highly developed countries. About 1 billion people worldwide have vitamin D deficiency, while $50 \%$ of the population has vitamin D insufficiency. The fact that exposure of the skin to UVB radiation, wavelengths that cause mutations in the DNA of epidermal cells, is also the source of vitamin D is problematic. Can the average person finely calibrate $0.2 \mathrm{~min}$ imal erythema dose, the point at which vitamin D synthesis occurs without perceptible DNA damage? For relevant nonskeletal conditions or diseases such as multiple sclerosis, Alzheimer's disease, or even ARDS, it is unknown whether low vitamin D status causes the disease or the disease causes the low vitamin D status. Communication with patients about vitamin D calls for judgment and individualization in patient care, including more nuanced advice about sun exposure.

\section{Compliance with Ethical Standards}

Human and Animal Rights and Informed Consent This article does not contain any studies with human or animal subjects performed by any of the authors.

\section{References}

Papers of particular interest, published recently, have been highlighted as:

- Of importance

•- Of major importance

1. DeLuca HF. Overview of general physiologic features and functions of vitamin D. Am J Clin Nutr. 2004;80(6):1689S-96S. https://doi.org/10.1093/ajen/80.6.1689S. This is a generally helpful primer on the classic functions and understanding of vitamin D.

2. Jorde R, Grimnes G. Vitamin D and health: the need for more randomized controlled trials. J Steroid Biochem Mol Biol. 2015;148:269-74. https://doi.org/10.1016/j.jsbmb.2015.01.021.

3. Jorde R, Grimnes G. Serum cholecalciferol may be a better marker of vitamin D status than 25-hydroxyvitamin D. Med Hypotheses. 2018;111:61-5. https://doi.org/10.1016/j.mehy.2017.12.017.

4. Brustad N, Garland J, Thorsen J, Sevelsted A, Krakauer M, Vinding RK, et al. Effect of high-dose vs standard-dose vitamin D supplementation in pregnancy on bone mineralization in offspring until age 6 years: a prespecified secondary analysis of a double-blinded, Randomized Clinical Trial. JAMA Pediatr. 2020;174(5):419-27. https://doi.org/10.1001/jamapediatrics.2019. 6083.

5.• Wheeler BJ, Snoddy AME, Munns C, Simm P, Siafarikas A, Jefferies C. A brief history of nutritional rickets. Front Endocrinol (Lausanne). 2019;10:795. https://doi.org/10.3389/fendo.2019. 00795. An important update on current issues in vitamin D status in multiple populations.

6. Sizar O, Khare S, Goyal A, Bansal P, Givler A. Vitamin D deficiency. StatPearls. Treasure Island (FL): StatPearls Publishing Copyright (C) 2020, StatPearls Publishing LLC.; 2020.

7. Institute of Medicine Committee to Review Dietary Reference Intakes for Vitamin D, Calcium. The National Academies Collection: Reports funded by National Institutes of Health. In: Ross AC, Taylor CL, Yaktine AL, Del Valle HB, editors. Dietary Reference Intakes for Calcium and Vitamin D. Washington (DC): National Academies Press (US) Copyright (C) 2011, National Academy of Sciences.; 2011. Reference text for clinical vitamin D measurement values.

8. NIST Releases Vitamin D Standard Reference Material. NIST July 14, 2009. https://www.nist.gov/news-events/news/2009/07/nistreleases-vitamin-d-standard-reference-material

9. Sempos CT, Binkley N. 25-Hydroxyvitamin D assay standardisation and vitamin D guidelines paralysis. Public Health Nutr. 2020;23(7):1153-64. https://doi.org/10.1017/ s1368980019005251.

10.• Sassi F, Tamone C, D'Amelio P. Vitamin D: nutrient, hormone, and immunomodulator. Nutrients. 2018;10(11). https://doi.org/10. 3390/nu10111656. Important discussion of vitamin D and immune function.

11. Scott JF, Das LM, Ahsanuddin S, Qiu Y, Binko AM, Traylor ZP, et al. Oral vitamin $D$ rapidly attenuates inflammation from sunburn: an interventional study. J Investig Dermatol. 2017;137(10):207886. https://doi.org/10.1016/j.jid.2017.04.040. 
12. Dombrowski Y, Peric M, Koglin S, Ruzicka T, Schauber J. Control of cutaneous antimicrobial peptides by vitamin D3. Arch Dermatol Res. 2010;302(6):401-8. https://doi.org/10.1007/s00403-010-1045-4.

13.• Lucas RM, Norval M, Neale RE, Young AR, de Gruijl FR, Takizawa Y, et al. The consequences for human health of stratospheric ozone depletion in association with other environmental factors. Photochem Photobiol Sci. 2015;14(1):53-87. https://doi. org/10.1039/C4PP90033B. A very thorough review of ultraviolet light effects on multiple physiological endpoints.

14. Tongkao-On W, Carter S, Reeve VE, Dixon KM, GordonThomson C, Halliday GM, et al. CYP11A1 in skin: an alternative route to photoprotection by vitamin D compounds. J Steroid Biochem Mol Biol. 2015;148:72-8. https://doi.org/10.1016/j. jsbmb.2014.11.015.

15. Wei R, Christakos S. Mechanisms underlying the regulation of innate and adaptive immunity by Vitamin D. Nutrients. 2015;7(10):8251-60. https://doi.org/10.3390/nu7105392.

16. Koivisto O, Hanel A, Carlberg C. Key Vitamin D Target genes with functions in the immune system. Nutrients. 2020;12(4). https://doi. org/10.3390/nu12041140.

17. Comberiati P, Peroni DG. Vitamin D Supplementation in pregnancy does not prevent school-age asthma. Allergy. 2020;75. https:// doi.org/10.1111/all.14337.

18. Manousaki D, Paternoster L, Standl M, Moffatt MF, Farrall M, Bouzigon E, et al. Vitamin D levels and susceptibility to asthma, elevated immunoglobulin E levels, and atopic dermatitis: a Mendelian randomization study. PLoS Med. 2017;14(5): e1002294. https://doi.org/10.1371/journal.pmed.1002294.

19. Study Questions the Benefits of Vitamin D and Omega 3 Supplements. CardioSmart News American College of Cardiology. Washington, D.C. November 13, 2018. https://www. cardiosmart.org/news/2018/10/study-questions-the-benefits-ofvitamin-d-and-omega-3-supplements

20. Dawodu A, Salameh KM, Al-Janahi NS, Bener A, Elkum N. The effect of high-dose postpartum maternal vitamin D supplementation alone compared with maternal plus infant vitamin D supplementation in breastfeeding infants in a high-risk population. A Randomized Controlled Trial. Nutrients. 2019;11(7). https://doi. org/10.3390/nu11071632.

21. AAD Position Statement Vitamin D. https://assets.ctfassets. net/1 ny4yoiyrqia/2 VuIeOfXmKWBV12XTVYpXo/ dfff5f47b0dddfb82676270505afd09f/ps-vitamin_d_postition statement.pdf

22. Ultraviolet (UV) index. World Health Organization. 16 October 2017. https://www.who.int/news-room/q-a-detail/ultraviolet-(uv)index

23. Macdonald HM, Mavroeidi A, Fraser WD, Darling AL, Black AJ, Aucott L, et al. Sunlight and dietary contributions to the seasonal vitamin D status of cohorts of healthy postmenopausal women living at northerly latitudes: a major cause for concern? Osteoporos Int. 2011;22(9):2461-72. https://doi.org/10.1007/s00198-010-1467-z.

24. Maurya VK, Bashir K, Aggarwal M. Vitamin D microencapsulation and fortification: trends and technologies. J Steroid Biochem Mol Biol. 2020;196:105489. https://doi.org/10.1016/j.jsbmb.2019.105489.

25. How to get vitamin D from sunlight. NHS. Reviewed: 31 August 2018. https://www.nhs.uk/live-well/healthy-body/how-to-getvitamin-d-from-sunlight/.

26. Passeron T, Bouillon R, Callender V, Cestari T, Diepgen TL, Green $\mathrm{AC}$, et al. Sunscreen photoprotection and vitamin D status. Br J Dermatol. 2019;181(5):916-31. https://doi.org/10.1111/bjd.17992.

27.• Fajuyigbe D, Young AR. The impact of skin colour on human photobiological responses. Pigment Cell Melanoma Res. 2016;29(6):607-18. https://doi.org/10.1111/pcmr.12511. An important discussion of study protocol variables and their influence on policy.
28.• Young AR, Greenaway J, Harrison GI, Lawrence KP, Sarkany R, Douki T, et al. Sub-optimal application of a high SPF sunscreen prevents epidermal DNA damage in vivo. Acta Derm Venereol. 2018;98(9):880-7. https://doi.org/10.2340/00015555-2992. Highly relevant study that examines real life use of sunscreen.

29. Young AR, Narbutt J, Harrison GI, Lawrence KP, Bell M, O'Connor $\mathrm{C}$, et al. Optimal sunscreen use, during a sun holiday with a very high ultraviolet index, allows vitamin D synthesis without sunburn. Br J Dermatol. 2019;181(5):1052-62. https://doi.org/ 10.1111/bjd.17888.

30. Katiyar SK, Matsui MS, Mukhtar H. Kinetics of UV light-induced cyclobutane pyrimidine dimers in human skin in vivo: an immunohistochemical analysis of both epidermis and dermis. Photochem Photobiol. 2000;72(6):788-93.

31. Narbutt J, Philipsen PA, Lesiak A, Sandberg Liljendahl T, Segerback D, Heydenreich J, et al. Children sustain high levels of skin DNA photodamage, with a modest increase of serum 25-hydroxyvitamin D3, after a summer holiday in Northern Europe. Br J Dermatol. 2018;179(4):940-50. https://doi.org/10.1111/bjd.16668.

32. Munns CF, Shaw N, Kiely M, Specker BL, Thacher TD, Ozono K, et al. Global consensus recommendations on prevention and management of nutritional rickets. J Clin Endocrinol Metab. 2016;101(2):394-415. https://doi.org/10.1210/jc.2015-2175.

33. Dixon KM, Tongkao-On W, Sequeira VB, Carter SE, Song EJ, Rybchyn MS, et al. Vitamin D and death by sunshine. Int J Mol Sci. 2013;14(1):1964-77. https://doi.org/10.3390/ijms14011964.

34. Jagoda SV, Dixon KM. Protective effects of 1,25 dihydroxyvitamin D3 and its analogs on ultraviolet radiation-induced oxidative stress: a review. Redox Rep. 2020;25(1):11-6. https://doi.org/10.1080/ 13510002.2020 .1731261$.

35. Slominski AT, Chaiprasongsuk A, Janjetovic Z, Kim TK, Stefan J, Slominski RM, et al. Photoprotective properties of vitamin D and lumisterol hydroxyderivatives. Cell Biochem Biophys. 2020;78: 165-80. https://doi.org/10.1007/s12013-020-00913-6.

36. Xiang F, Lucas R, de Gruijl F, Norval M. A systematic review of the influence of skin pigmentation on changes in the concentrations of vitamin D and 25-hydroxyvitamin D in plasma/serum following experimental UV irradiation. Photochem Photobiol Sci. 2015;14(12):2138-46. https://doi.org/10.1039/c5pp00168d. A substantial review of skin pigmentation and vitamin $D$ levels..

37. Marwaha RK, Sreenivas V, Talwar D, Yenamandra VK, Challa A, Lakshmy R, et al. Impact of solar ultraviolet B radiation (290-320 $\mathrm{nm}$ ) on vitamin $\mathrm{D}$ synthesis in children with type IV and V skin. Br J Dermatol. 2015;173(2):604-6. https://doi.org/10.1111/bjd.13887.

38. Au LE, Harris SS, Dwyer JT, Jacques PF, Sacheck JM. Association of serum 25-hydroxyvitamin $\mathrm{D}$ with race/ethnicity and constitutive skin color in urban schoolchildren. J Pediatr Endocrinol Metab. 2014;27(11-12):1095-100. https://doi.org/10.1515/jpem-2014-0068.

39.• Young AR, Morgan KA, Ho TW, Ojimba N, Harrison GI, Lawrence KP, et al. Melanin has a small inhibitory effect on cutaneous vitamin D synthesis: a comparison of extreme phenotypes. J Investig Dermatol. 2020;140(7):1418-26.e1. https://doi.org/10. 1016/j.jid.2019.11.019. A critically important study of melanin, pigmentation levels, skin physiology and vitamin $D$.

40. Jung HC, Seo MW, Lee S, Kim SW, Song JK. Vitamin D(3) Supplementation reduces the symptoms of upper respiratory tract infection during winter training in vitamin D-insufficient taekwondo athletes: a randomized controlled trial. Int J Environ Res Public Health. 2018;15(9). https://doi.org/10.3390/ijerph15092003.

41. Dancer RC, Parekh D, Lax S, D'Souza V, Zheng S, Bassford CR, et al. Vitamin D deficiency contributes directly to the acute respiratory distress syndrome (ARDS). Thorax. 2015;70(7):617-24. https://doi.org/10.1136/thoraxjnl-2014-206680.

42. Martineau AR, Jolliffe DA, Hooper RL, Greenberg L, Aloia JF, Bergman P, et al. Vitamin D supplementation to prevent acute respiratory tract infections: systematic review and meta-analysis 
of individual participant data. Bmj. 2017;356:i6583. https://doi.org/ 10.1136/bmj.i6583.

43.• Grant WB, Lahore H, McDonnell SL, Baggerly CA, French CB, Aliano JL, et al. Evidence that vitamin D supplementation could reduce risk of influenza and COVID-19 infections and deaths. Nutrients. 2020;12(4). https://doi.org/10.3390/nu12040988. Of major importance, including the possible relationship between vitamin D levels and COVID-19.

44.• Jakovac H. COVID-19 and vitamin D-is there a link and an opportunity for intervention? Am J Physiol Endocrinol Metab. 2020;318(5):E589. https://doi.org/10.1152/ajpendo.00138.2020.
Of major importance, including the possible relationship between vitamin D levels and COVID-19.

45.• Panarese A, Shahini E. Letter: Covid-19, and vitamin D. Aliment Pharmacol Ther. 2020;51(10):993-5. https://doi.org/10.1111/apt. 15752. Of major importance, including the possible relationship between vitamin D levels and COVID-19.

Publisher's Note Springer Nature remains neutral with regard to jurisdictional claims in published maps and institutional affiliations. 